\title{
VACUUM IMPREGNATION: EMERGING TECHNOLOGY FOR OSMOTIC DEHYDRATION OF FRUITS AND VEGETABLES
}

\author{
R. Sasireka ${ }^{1}$ and Dr.S.Ganapathy ${ }^{2}$
}

Abstract In the osmotic treatment of foods, Vacuum Impregnation (VI) is the emerging technique that improves the air drying and osmotic dehydration (OD) of a porous product with a consequent change in food composition. Due to the action of hydrodynamic mechanisms (HDM) promoted by pressure changes, VI technique exchanges the internal gas or liquid occluded in open pores to an external liquid phase that consequently enhances the quality of the food by changing its composition. With the unique advantage of incorporating both osmosis and diffusion during its process, VI has a broad application in fruit and vegetable processing industries. This paper provides an overall review about the process and equipment details of the VI and their application in food industries. Also, the main factors affecting the process and the response of porous fruits and vegetables to VI processing has been discussed.

\section{INTRODUCTION}

Dehydration is one of the most important operations that are widely practiced because of considerable saving in packaging, storage etc. Osmotic dehydration has received greater attention in recent years as an effective method for preservation of fruits and vegetables. Being a simple process, it facilitates processing of tropical fruits and vegetables such as banana, sapota, pineapple, mango, and leafy vegetables etc. with retention of initial fruit and vegetables characteristics viz., colour, aroma and nutritional compounds (Pokharkar \& Prasad, 1998). It involves dehydration of fruit slices in two stages, removal of water using as an osmotic agent (osmotic concentration) and subsequent dehydration in a dryer where moisture content is further reduced to make the product shelf stable (Ponting, 1973). Among developments in osmotic treatments of foods, vacuum impregnation (VI) is the newest. VI of a porous product consists of exchanging the internal gas or liquid occluded in open pores to an external liquid phase due to the action of hydrodynamic mechanisms (HDM) promoted by pressure changes (Fito, 1994; Fito \& Pastor, 1994).

The gas of the porous tissue expands and flows out in combination with the deformation relaxation phenomena (DRP) of the solid matrix. After restoring the atmospheric pressure, the

\footnotetext{
${ }^{1}$ M.Tech scholar, Tamil Nadu Agricultural University, Coimbatore, Tamil Nadu, India

${ }^{2}$ Professor \& Head, Dept. Of Food and Agricultural Process Engg., Tamil Nadu Agricultural University, Coimbatore, Tamil Nadu, India
} 
tissue contracts and the VI solution penetrates into the previously air-filled pores (Fito et al., 1996; Guillemin et al., 2008). The volume of externally penetrating liquid can account for almost the total volume of the intercellular space that was initially filled with gas (Fito, 1994). Even immersion of porous plant tissues in a liquid results in an influx of liquid due to capillary forces which are limited to the pores close of the surface. The mass transfer phenomena are described as hydrodynamic mechanisms (HDM). The VI mass transfer process is affected by several factors, including the process duration, the process temperature, the subatmospheric pressure level, the form and shape, the samples' mechanical response, the porosity, the size of the pores and the composition of the applied VI solution (Zhao and Xie, 2004).VI results in final product with a better organoleptic quality, texture, better nutrition, microbial safety. VI reduces discoloration due to removal of oxygen from the pores of the fruits and vegetables. A comparison of VI with the osmotic dehydration at atmospheric pressure in terms of time scale, driving force, controlling mechanism, equilibrium condition, water loss rate, solid gain has been presented in Table 1.

\section{TABLE $1^{\mathrm{a}}$}

Characteristics of a practical definition for different gas-liquid exchange processes

\begin{tabular}{|l|l|l|l|l|l|l|}
\hline Process & $\begin{array}{l}\text { Time } \\
\text { scale }\end{array}$ & Driving force & $\begin{array}{l}\text { Controlling } \\
\text { mechanism }\end{array}$ & $\begin{array}{l}\text { Equilibrium } \\
\text { condition }\end{array}$ & $\begin{array}{l}\text { Water } \\
\text { loss rate }\end{array}$ & $\begin{array}{l}\text { Solid } \\
\text { gain }\end{array}$ \\
\hline $\begin{array}{l}\text { Vacuum } \\
\text { impregnation }\end{array}$ & Minutes & $\begin{array}{l}\text { Pressure } \\
\text { gradients } \\
\text { and capillary } \\
\text { action }\end{array}$ & HDM & $\Delta \mathrm{P}_{\text {int-ext }}=0$ & High & Low \\
\hline $\begin{array}{l}\text { Osmotic } \\
\text { dehydration }\end{array}$ & Hours & $\begin{array}{l}\text { Capillary } \\
\text { action } \\
\text { and chemical } \\
\text { potential of } \\
\text { components } \\
\text { (mainly } \\
\text { water) }\end{array}$ & $\begin{array}{l}\text { PDM and } \\
\text { CMD }\end{array}$ & $\Delta \mathrm{a}_{\mathrm{w}}=0$ & Middle & Middle \\
\hline
\end{tabular}

$\left({ }^{\mathrm{a}}\right.$ Yanyun Zhao and Jing Xie, 2004)

\section{MECHANISM INVOLVED IN VI PROCESS}

VI intensifies capillary flow and mass transfer rate. The Hydro Dynamic Mechanism (HDM) plays an important role in vacuum solid-liquid operations, because the changes of pressure in the system produce strong driving forces responsible for mass transfer. There is a fast mass transfer mechanism, called HDM, which occurs when porous structures are immersed in a liquid phase. This involves the inflow of the external liquid throughout the capillary pores, controlled by the expansion/compression of the internal gas. This mechanism is responsible for the VI processes of porous products when low pressures are imposed in a solid-liquid system (vacuum step) followed by the restoration of atmospheric pressure (Fito et al., 2001; Zhao \& Xie, 2004).

During the vacuum step, the internal gas in the product pores of the product is expanded and partially flows out. All this is coupled with the capillary penetration as a function of the interfacial tension of the liquid and the diameter of pores. In the atmospheric step, the residual gas is compressed, and the external liquid flows into the pores as a function of the compression ratio. Nevertheless, pressure changes can also promote deformations of the product because of 
the viscoelastic properties of its solid matrix. Coupling of HDM with the deformation-relaxation phenomena (DRP) of the product's solid matrix has been described and modeled, showing that volume changes at the end of the vacuum and the atmospheric steps, as well as the effective porosity affect the volume fraction of the product impregnated by the external liquid.

There are several factors which has been reported that affects the VI process (Fito et al., 1996). 1) Tissue structure (Pores and size distribution) 2) Viscoelastic property of the product 3) Initial composition of the sample 4) Type of impregnation solution used 5) Relaxation time of the solid matrix (a function of the mechanical properties of the material) 6) Size and shape of the sample

The concentration, temperature, solution to product ratio and agitation of an impregnation solution plays significant role in VI (Fito et al., 1998). Yang and Maguer (1992) reported that decrease in mass transfer occurred when the solution concentration reached 50-60\%. The distribution coefficient for water decreased with increasing temperature and syrup concentration, while distribution coefficient for solids increased with temperature and decreased with increase in syrup concentration (Sablani and Shafiur Rahman, 2003). Plant tissue cells placed in different kinds of solution react differently. A) Isotonic solution: same solute concentration inside and outside the cell membrane. B) Hypotonic solution: less solute molecules outside of the cell membrane than inside of it. C) Hypertonic solution: more solute concentration outside the cell membrane than inside of it. Figure 1 represents the different three solution and the movement of water across the cell membrane. The ratio of VI solution to product is an important parameter. A high solution to sample ratio ensures retention of a constant solution concentration during processing. Lenart and Flink (1984) suggested that a value of 4-6 might be optimal for best osmotic effect. Agitation of the impregnation solution affects water loss and solid gain in impregnation processing. Karanthanos et al., (1998) reported that water loss is higher in the region of turbulent rather than in laminar flow, i.e. VI processing can be hastened when the sample is agitated in solution. In some cases, the advantages of agitation do not justify the cost (Ponting et al., 1966).

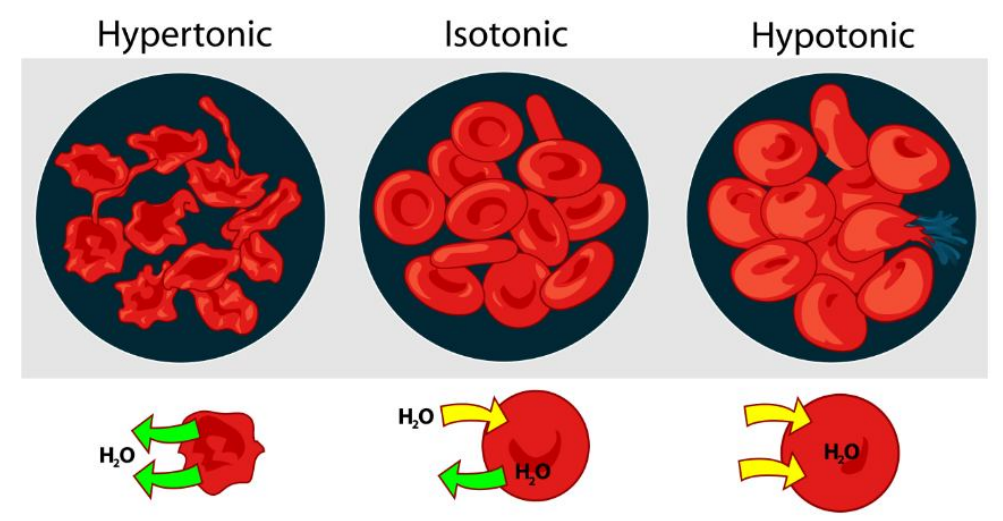

Figure 1. Type of impregnation solution and movement of water across the cell membrane (Source: www.studyblue.com)

Shi \& Fito (1993) reported that a high water loss can be obtained from low pressure systems. But solid gain differs only slightly between the vacuum and atmospheric pressure treatments, as the 
main factor influencing the solid gain is the biological microstructural characteristics of the plant tissues (Shi \& Fito, 1993). The higher the vacuum, the greater the volume of impregnated solution. The effect of impregnation time on sample deformation and on amount of solutes impregnated into samples depends on property of raw material, vacuum level and other factors. Different operating parameters based on the studies have been optimized. Table 2 gives the range of VI operating parameters commonly used in fruits and vegetables.

\section{TABLE $2^{\mathrm{a}}$}

Range of VI operation parameters commonly used in minimally processed and dehydrated fruits and vegetables

\begin{tabular}{|c|c|c|c|}
\hline \multirow[b]{2}{*}{ Parameters } & \multicolumn{3}{|l|}{ Conditions } \\
\hline & $\begin{array}{l}\text { Minimally } \\
\text { Products }\end{array}$ & Processed & Dehydrated Products \\
\hline Solution concentration & 20 to $<50^{\circ}$ Brix & & $50-75^{\circ}$ Brix \\
\hline Solution temperature & $20-50^{\circ} \mathrm{C}$ & & $20-50^{\circ} \mathrm{C}$ \\
\hline Vacuum level & 5-50 mbar & & $50-200 \mathrm{mbar}$ \\
\hline Vacuum time & $10-20$ minutes & & Usually 10-20 minutes \\
\hline Atmospheric restoration & $10-20 \mathrm{~min}$ & & Minutes to hours \\
\hline
\end{tabular}

$\left({ }^{a}\right.$ Summarized from Yanyun Zhao and Jing Xie, 2004)

\section{OPERATING PROCEDURES}

The operation is carried out in two steps after product immersion in a tank containing the liquid phase. In the first step, vacuum pressure (50-100 mbar) is imposed on the system for a short time in the closed tank, thus promoting the expansion and outflow of internal gas in the product. Gas release takes the product pore native liquid with it. In the second step, atmospheric pressure is restored in the tank for a time with compression leading to a great reduction in volume in the gas remaining in the pores, and thus to the subsequent influx of external liquid into the porous structure. Figure 2 and 3 represents experimental set up of vacuum impregnation system and automated vacuum controlled system that is being adopted during the processing of fruits and vegetables.
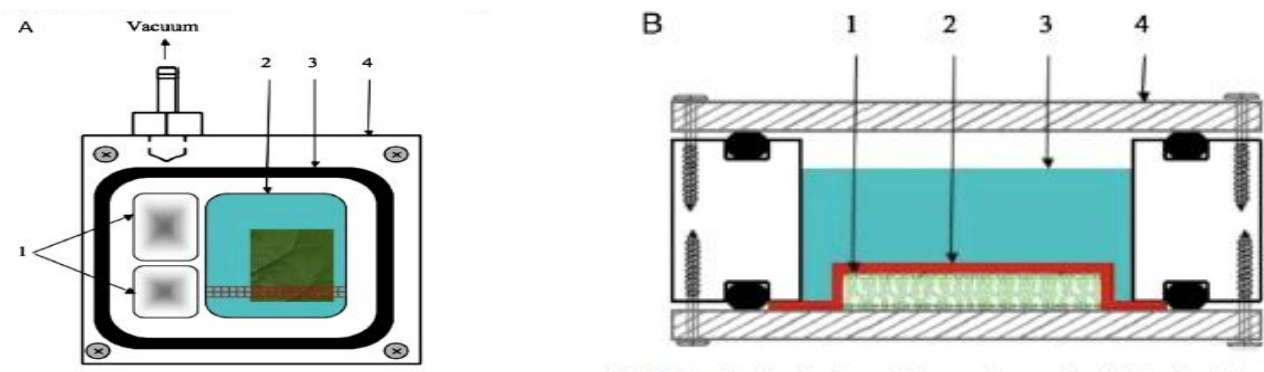
Figure 2. Schematic of the chamber used for vacuum impregnation. (A) Top view: 1. Vacuum pre-chambers, 2. Main chamber containing sample and impregnating solution, 3. O-ring, 4. Plastic frame; (B) Cross section: 1. Sample, 2. Plastic fastener, 3. Impregnating solution, 4. Upper and lower glass plates sealed to the plastic frame by the O-ring. (Valentina Panarese et al., 2012)

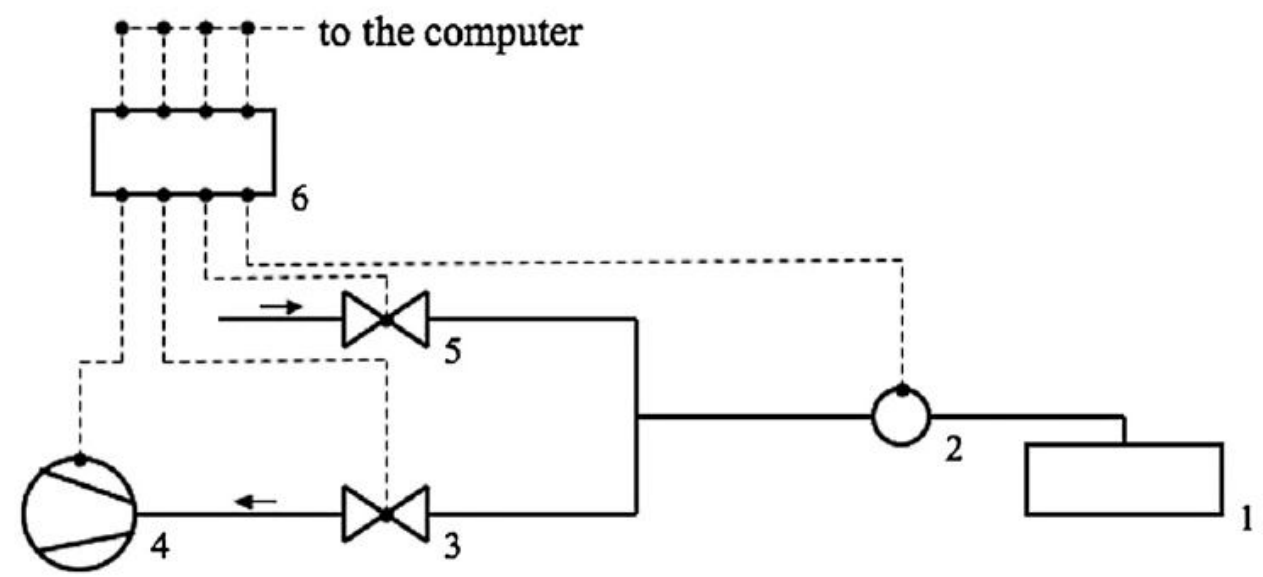

Figure 3. Schematic illustration of the AVCS: 1. Treatment chamber, 2. Pressure transmitter, 3. Valve regulating air outlet, 4. Vacuum pump, 5. Valve regulating air inlet, 6. PLC. Arrows indicate the direction of air flow. Solid lines represent pneumatic connections, dashed lines represent electrical connections (Valentina Panarese et al., 2012)

\section{RESPONSE OF FRUITS AND VEGETABLES}

The response of many fruits and vegetables to the VI processing with respect to deformation and impregnation has been characterized mathematically and experimentally. Impregnated sample volume fraction, sample relative volume of deformation, and effective porosity strongly depend on raw material characteristics (porosity, size, and shape), and VI conditions (type and concentration of solution, vacuum level, and time). The volume fraction of a sample (X) impregnated by external liquid when mechanical equilibrium is achieved has been modeled as a function of compression ratio, sample effective porosity, and sample volume deformation at the end of the process, and is described in Eq.1 (Fito et al., 1996).

$$
\varepsilon_{\mathrm{e}}=\frac{(\mathrm{x}-\mathrm{\gamma}) \mathrm{r}+\mathrm{\gamma}_{1}}{\mathrm{r}-1}
$$

$\mathrm{X}=$ volumetric fraction of sample occupied by liquid as a result of HDM at the end of the process $\left(\mathrm{m}^{3}\right.$ of liquid $/ \mathrm{m}^{3}$ of sample at $\left.\mathrm{t}=0\right) ; \varepsilon_{\mathrm{e}}=$ effective porosity $\left(\mathrm{m}^{3}\right.$ of gas inside the pores $/ \mathrm{m}^{3}$ of sample); $\square_{1}=$ relative samples volume deformation at the end of the vacuum period $\left(\mathrm{m}^{3}\right.$ of sample deformation $/ \mathrm{m}^{3}$ of sample at $\left.\mathrm{t}=0\right) ; \gamma=$ final relative volume sample deformation $\left(\mathrm{m}^{3}\right.$ of sample deformation $/ \mathrm{m}^{3}$ of sample at $\left.\mathrm{t}=0\right) ; \mathrm{r}=$ compression ratio $(\sim$ atmospheric pressure/vacuum pressure).

In general, positive volume deformations decrease in volume) at the end of the vacuum step were obtained due to deformation of the solid matrix associated with depression and gas expansion. At the end of the compression period, deformation was negative or positive depending on the nature 
of fruit. With reference to the liquid phase fluxes, most fruits received a net gain of liquid at the end of vacuum step due to loss of native liquid as pore volume initially occupied by native liquid is available for impregnation by the external solution. The expelled native liquid was then replaced by the external one throughout the compression step.

Physico-chemical properties: Texture, total acids, and color are among those physicochemical properties most affected by VI as a result of change in product density, especially in highly porous samples. The texture quality of VI processed products is significantly related to the type of VI solutions used. VI with hypotonic or isotonic solutions does not change the firmness of fresh apples (Martinez-Monzo et al., 1998; Xie \& Zhao, 2003a), but the firmness is strongly reduced when VI with hypertonic solution, and sample dehydration occurs simultaneously. The dehydration further promoted the losses of cell turgor and elasticity, the alteration of cell resistance, the increase in viscous character, the changes in air and liquid volume fractions in the product, and the changes in sample size and shape (Fito et al., 2000; Pitt, 1992).

Thermal properties: Thermal conductivity and diffusivity are greatly dependent on product composition and structure. Fito et al. (2000) reported that VI with isotonic solutions increases thermal conductivity because of the gas replacement, but only causes slight changes in thermal diffusivity due to the simultaneous density increase. Martinez-Monzo et al. (2000) also showed that VI results in a 15-24\% increase in thermal conductivity of apples submitted to VI processing, whereas the thermal diffusivity only changed $2-4 \%$.

\section{USE OF VI IN FOOD PROCESSING}

Energy saving: VI reduces volume of the products thereby saving in the cost of processing, storage and transport. Pretreatment of fruits and vegetables with VI could reduce the energy consumption during post drying process as VI removes most of the water from the product (Yanyun Zhao and Jing Xie, 2004). Dehydrated fruits and vegetables can be used as a food ingredient in many products, have also been added to cereals, granola bars, baked goods and mixes, and can even be eaten out of hand.

Food fortification: VI forms the best tool for food fortification process. Calcium can be incorporated into the cellular structure of the pineapple snacks by means of vacuum pulsed osmotic dehydration (Marla Mateus de Lima et al., 2016). The dehydration of samples implies a decrease in the cellular respiration rate and, consequently, an increase in the shelf-life of the processed fruit, both of which are more marked if calcium is added to the sample (M.J. Moraga et al., 2008). Erihemu et al., (2012) reported that the iron content of VI potatoes increased with vacuum time and restoration time. VI can also be used as a tool to produce Probiotic enriched fruit products. Betoret et al., (2003) reported that using VI dehydrated apple with the microbial content (S. cerevesiae and L.Casei spp. rhamnosus) ranging $10^{6}-10^{7} \mathrm{cfu} / \mathrm{g}$, which corresponds to the values found in commercial dairy products.

Food salting: A brine VI process has been developed (Chiralt \& Fito, 1997) to reduce brining time, taking advantage of the salt uptake by hydrodynamic mechanisms (HDM) ocuuring in capillary pores by the action of pressure gradients (Ch. Gonzalez et al., 1999). By using VI 
techniques in salting processes of porous food, faster salting kinetics can be obtained with a more even salt distribution in the product and with increased process yields (Chiralt et al., 2000).

Quality of the products: VI pretreatment has been studied to improve quality of frozen fruits and vegetables by mainly reducing drip loss and improving texture quality, as well as saving energy consumption during freezing (Bengtsson \& Fernquist, 1971; Biswal et al., 1991; Bolin \& Huxsoll, 1993; Garrote \& Bertone, 1989; Lenart \& Flink, 1984; Maestrelli et al., 2001; MartinezMonzo et al., 1998; Sormani, Maffi, Bertolo, \& Torreggiani, 1999; Torreggiani, 1995; Torreggiani \& Bertolo, 2001; Xie \& Zhao, 2003b). VI can be considered as a tool in minimal processing of fruits or vegetables that is much more effective than the conventional soaking of the fruit in the active component solution (C.E.Tamer and Ö.U. Çopur, 2010).

\section{SUGGESTIONS FOR FUTURE STUDIES}

VI technique has been considered to improve product quality, modify product formulation, and save energy in some of the fruit and vegetable processing. By selecting appropriate process conditions, the specific application of VI can be controlled and optimized. However, extensive studies are still required in order to fully taking advantage of its unique features and applying in large-scale industrial operations.

Control of different types of VI solutions (isotonic, hypertonic, and hypotonic) on mass transfer rate is important, especially when VI is used to develop compositionally formulated or minimally processed fruit and vegetable products. An optimal mass transfer to ensure sufficient solutes getting into the products without negative impacts on the physicochemical and sensory properties is the key for its successful application (Yanyun Zhao and Jing Xie, 2004).

One major issue in the large-scale industrial application of VI and any other osmotic processing is the management of the remained solution at the end of the process. Valdez- Fragoso et al. (2002) found that water loss, solids gain, and color of dehydrated apple cubes obtained in osmotic dehydration process with reused osmotic solution are similar to those obtained with fresh osmotic solution. Unfortunately, the recycle of osmotic solution is still one of the main shortcomings and challenges. Techniques to treat the waste concentrated solutions, especially for the mixture solution, are very important and need more studies. If raw materials are contaminated, it may contaminate VI solutions during VI processing. Further contamination would occur if contaminated solutions are to be reused. Very little study was reported in this aspect, thus requiring a substantial research effort.

Completely immersing the products under the solution and keeping good contact throughout the process are essential for a VI processing. Current industry operation has used stirring or compressing for this purpose, but it adds more cost and may also damage the products. Other approaches need to be considered.

\section{CONCLUSION}

Although vacuum impregnation was for the first time proposed at least 20 years ago, is still considered an emerging technology with high potential applications. Vacuum impregnation 
process is finding huge application in food processing industries for dehydration, nutrition enrichment, pre-treatment methods, debittering processes, $\mathrm{pH}$ reduction in vegetables, causing antimicrobial effect, changing microstructure of the products, probiotics food production, food salting etc. VI also has some technical problems as reported by Zhao \& Xie (2004). However, VI is a very complex treatment and its results are affected from several external and internal variables. VI would find more application when it is used with the controlled mass transfer rate and better use of osmotic solutions. Further studies can be made to minimize the technical issues in VI.

\section{ACKNOWLEDGEMENT}

The authors wish to express sincere appreciations to Mr.Jagadeesh Kumar.K for editorial review and suggestions.

\section{REFERENCES}

[1] Yanyun Zhao and Jing Xie, "Practical applications of vacuum impregnation in fruit and vegetable processing," Trends in Food Science \& Technology, volume 15, pp. 434-451, 2004.

[2] Canan Ece Tamer \& Bige İncedayı \& Berivan Yıldız \& Ömer Utku Çopur, "The Use of Vacuum Impregnation for Debittering Green Olives,” Food Bioprocess Technology, vol 6, pp. 3604-3612, 2013.

[3] Betoret , L. Puente, M.J. D $\square$ az, M.J. Pagan, M.J. Garcia, M.L. Gras, J. Martınez-Monzo, P. Fito, "Development of probiotic-enriched dried fruits by vacuum impregnation," Journal of Food Engineering, vol. 56, pp. 273-277, 2003.

[4] M.J. Moraga, G. Moraga, P.J. Fito, N. Martínez-Navarrete, "Effect of vacuum impregnation with calcium lactate on the osmotic Dehydration kinetics and quality of osmodehydrated grapefruit," Journal of Food Engineering, vol. 90, pp. 372-379, 2009.

[5] Anne Guillemin, Pascal Degraeve, Claude Noel, Remi Saurel, "Influence of impregnation solution viscosity and osmolarity on solute uptake during vacuum impregnation of apple cubes (var. Granny Smith)," Journal of Food Engineering, vol.86, pp. 475-483, 2008

[6] Erihemu, K. Hironaka, Y. Oda, H. Koaze, "Iron enrichment of whole potato tuber by vacuum impregnation," LWT - Food Science and Technology, vol 59, pp. 504-509, 2014

[7] A.chiralt, P.Fito, J.M. Barat, A.Andres, C.Gonzalez-Matinez, I.Escriche, M.M.Camacho, "Use of Vacuum impregnation in food salting process," Journal of Food Engineering, vol. 49, pp. 141-151, 2001.

[8] C.E. Tamer and Ö.U. Çopur, "Use of Vacuum Impregnation for Minimally Processed Fruits and Vegetables," Proc. $6^{\text {th }}$ International Postharvest Symposium, Acta Hort. 877, ISHS 2010

[9] M. Gras, D. Vidal-Brotons, N. Betoret, A. Chiralt, P. Fito, "The response of some vegetables to vacuum impregnation,” Innovative Food Science \& Emerging Technologies vol.3, pp. 263-269, 2002

[10] Ch. Gonzalez, C. Fuentes, A. AndreHs, A. Chiralt, P. Fito, "Effectiveness of vacuum impregnation brining of Manchego-type curd,” International Dairy Journal, vol.9, pp.143-148, 1999.

[11] J. Martinez-Monzo, J.M. Barat, C. Gonzalez-Martinez, A. Chiralt, P. Fito, "Changes in thermal properties of apple due to vacuum impregnation," Journal of Food Engineering, vol.43, pp. 213-218, 2000.

[12] Marla Mateus de Lima, Giustino Tribuzi, Jose Antonio Ribeiro de Souza, Ivan Gonçalves de Souza, Joao Borges Laurindo, Bruno Augusto Mattar Carciofi, "Vacuum impregnation and drying of calcium-fortified pineapple Snacks," LWT - Food Science and Technology, vol.72, pp.501-509, 2016

[13] Pedro Fito, Amparo Chiralt, Jose M.Barat, Ana Andres, Javier Martinez-Monzo, Nuria Martinez-Navarrete, "vacuum impregnation for development of new dehydrated products," Journal of Food Engineering, vol.49, pp. 297-302, 2001

[14] Erihemu \& Kazunori Hironaka \& Hiroshi Koaze \& Yuji Oda \& Kenichiro Shimada, "Zinc enrichment of whole potato tuber by vacuum impregnation," Journal of Food Science and Technology, vol. 52 no.4 pp: 2352-2358, April 2015.

[15] Lilia Neri, Letizia Di Biase, Giampiero Sacchetti, Carla Di Mattia, Veronica Santarelli, Dino Mastrocola, Paola Pittia, "Use of vacuum impregnation for the production of high quality freshlike apple products," Journal of Food Engineering, vol.179, pp. 98-108, 2016

[16] P. Fito, A. Andres, A. Chiralt \& P. Pardo, "Coupling of Hydrodynamic Mechanism and DeformationRelaxation Phenomena During Vacuum treatments in Solid Porous Food-Liquid Systems," Journal of Food Engineering, vol.21, pp:229-240, 1996. 
[17] A. Derossi \& T. De Pilli \& C. Severini, "Application of Vacuum Impregnation Techniques to Improve the pH Reduction of Vegetables: Study on Carrots and Eggplants," Food Bioprocess Technology, vol.6, pp.3217-3226, 2013

[18] X. Q. Shi, P. Fito \& A. Chiralt, "Influence of vacuum treatment on mass transfer during osmotic dehydration of fruits," Food Research International, Vol. 28, No. 5, pp. 445-454, 1995.

[19] H. Mujica-Paz, A. Valdez-Fragoso, A. Lopez-Malo, E. Palou, J. Welti-Chanes, "Impregnation and osmotic dehydration of some fruits: effect of the vacuum pressure and syrup concentration," Journal of Food Engineering, vol.57, pp.305-314, 2003.

[20] Valentina Panarese, Petr Dejmek, Pietro Rocculi, Federico Gómez Galindo, "Microscopic studies providing insight into the mechanisms of mass transfer in vacuum impregnation," Innovative Food Science and Emerging Technologies, vol.18 pp.169-176, 2013.

[21] J. Moreno, R. Simpson, M. Sayas, I. Segura, O. Aldana, S. Almonacid, "Influence of ohmic heating and vacuum impregnation on the osmotic dehydration kinetics and microstructure of pears (cv. Packham's Triumph)," Journal of Food Engineering, vol.104, pp.621-627, 2011.

[22] H. Mujica-Paz, A. Valdez-Fragoso, A. Lopez-Malo, E. Palou, J. Welti-Chanes," Impregnation properties of some fruits at vacuum pressure," Journal of Food Engineering, vol.56, pp.307-314, 2003

[23] A. Derossi, T. De Pilli and C. Severini, "The Application of Vacuum Impregnation Techniques in Food Industry," intechopen.com/books/scientific-health-and-social-aspects-of-the-food-industry

[24] Elżbieta Radziejewska-Kubzdela, Róża Biegańska-Marecik and Marcin Kidoń, "Applicability of Vacuum Impregnation to Modify Physico-Chemical, Sensory and Nutritive Characteristics of Plant Origin Products-A Review,” International journal of Molecular sciences, vol.15 pp: 16577-16610, 2014. 